\title{
Predictors of Sub-Optimal CD4 Recovery during the First Six Months of Anti-Retroviral Treatment (ART) in HIV Infected Children: A Retrospective Cross Sectional Study from Tikur Anbessa Tertiary Hospital, Addis Ababa, Ethiopia
}

\section{Abebe Sorsa*}

Department of Pediatrics and Child Health, Asella College of Health Science, Arsi University, Asella, Ethiopia

\begin{abstract}
Background: Highly active anti-retroviral therapy (HAART) has brought significant change in reducing morbidity and mortality among children living with HIVIAIDS. Decisions concerning initiation and/or shifting of antiretroviral therapy (ART) are guided by monitoring the laboratory parameters of plasma HIV RNA (viral load) and CD4+ T cell count in addition to the patient's over all clinical response. The demonstrations of the prognostic value of the CD4 cell count was of major importance in the development of therapeutic strategies. Therefore, the objective of this study was to assess factors predicting suboptimal CD4 cell recovery during first six months of ART.
\end{abstract}

Methods: The study is retrospective cross sectional study to assess factors predicting suboptimal CD4 cell recovery. Medical records of patients' were retrieved and important variables are captured to standard questionnaire tool. T-test is used to assess changes in CD4 cell count after initiation of ART. Binary logistic and multiple regressions were used to assess factors predicting CD4 cell recovery.

Results: Data of 360 children were analyzed. CD4 cell count at the start of HAART ranged from 3-2003 cell/mL with an interquartile range of 231-317 cell/mL. After 6 months of HAART, the CD4 cell count has increased ranging from $71-2300 \mathrm{cell} / \mathrm{mL}$ with inter quartile range of $458-612 \mathrm{cell} / \mathrm{mL}$ and mean CD4 cell count difference of $230,95 \% \mathrm{Cl}$ (199.414-260.613); $P<0.001$. Advanced clinical stage of the disease, severe degree of immunosupression, presence of anemia, presence of chronic diarrhea at base line, poor weight gain during first six months of HAART adversely affect the trends of CD4 recovery.

Conclusion: Our study demonstrated that advanced clinical stage of the disease, severe degree of immunosupression, presence of anemia at baseline and presence of chronic diarrhea, poor weight gain during first six months of HAART were factors adversely affect the trends of CD4 recovery.

Keywords: HIV/AIDS; HAART/ART; Suboptimal CD4 recovery; Predictors; CD4 cell count recovery

Abbreviations: AIDS: Acquired Immunodeficiency Syndrome; ART: Antiretroviral Treatment; ARV: Antiretroviral Drug; HAART: Highly Active Antiretroviral Therapy; HIV: Human Immune-Virus; MTCT: Mother to Child Transmission; NNRTI: Non-Nucleoside Reverse Transcriptase Inhibitors; NRTI: Nucleoside Reverse Transcriptase Inhibitors; PMTCT: Prevention of Mother to Child Transmission; SD: Standard Deviation; TB: Tuberculosis; WHO: World Health Organization

\section{Introduction}

More than 2 million children are living with HIV/AIDS worldwide and more than $90 \%$ of them are living in sub-Saharan Africa [1]. More than $90 \%$ of children acquire the infection through mother to child HIV transmission (MTCT). Despite this, only $10 \%$ of HIVinfected pregnant ladies are offered any form of prevention of mother to child HIV transmission (PMTCT) in sub-Saharan countries $[1,2]$. Ethiopia has an estimated population of close 100 million people, of whom $44 \%$ are under 15years of age [2]. Currently 367,000 patients including 23,400 children under the age of 15 are taking ART. Based on the 2014 estimate, the 2014 ART need is 542, 121 for adults and 178,500 for children under 15 years of age. On the basis of the 20102014 strategic plan, ART coverage for adults has reached $76 \%$ but the coverage remains low (23.5\%) for children. If HAART is not started promptly, a third of children infected prenatally will not survive to their first birthday, and more than half will succumb to death by their second birthday [3-5]. Highly active anti-retroviral therapy (HAART) has brought significant change in reducing morbidity and mortality among children living with HIV/AIDS. Decisions concerning initiation and/or shifting of antiretroviral therapy (ART) are guided by monitoring the laboratory parameters of plasma HIV RNA (viral load) and CD4+ T cell count in addition to the patient's overall clinical status. Monitoring clinical and diagnostic progression of patients on anti-retroviral treatment (ART) is important to examine responses to the treatment and for clinical decision-making. The demonstrations of the prognostic value of the CD4 cell count was of major importance in the development of therapeutic strategies. Children's immune response to ART differs based on age at ART initiation and degree

*Corresponding author: Abebe Sorsa, Department of Pediatrics and Child Health Asella College of Health Science, Arsi University, Asella, Ethiopia, Tel: $+251-222$ 308-252; E-mail: nathanabebe08@gmail.com

Received August 23, 2017; Accepted August 28, 2017; Published September 14, 2017

Citation: Sorsa A (2017) Predictors of Sub-Optimal CD4 Recovery during the First Six Months of Anti-Retroviral Treatment (ART) in HIV Infected Children: A Retrospective Cross Sectional Study from Tikur Anbessa Tertiary Hospital, Addis Ababa, Ethiopia. J Blood Lymph 7: 178. doi: 10.4172/2165-7831.1000178

Copyright: ( 2017 Sorsa A. This is an open-access article distributed under the terms of the Creative Commons Attribution License, which permits unrestricted use, distribution, and reproduction in any medium, provided the original author and source are credited. 
Citation: Sorsa A (2017) Predictors of Sub-Optimal CD4 Recovery during the First Six Months of Anti-Retroviral Treatment (ART) in HIV Infected Children: A Retrospective Cross Sectional Study from Tikur Anbessa Tertiary Hospital, Addis Ababa, Ethiopia. J Blood Lymph 7: 178. doi: 10.4172/2165-7831.1000178

Page 2 of 5

of viral levels. As shown in recent adult studies, there are likely other baseline factors contributing to differential immunological responses. Baseline clinical and demographic factors have been used to predict mortality in HIV-infected children on ART [2]. However, few baseline clinical characteristics other than age, $\mathrm{CD} 4 \%$ and viral response have been examined as potential predictors of weight and immune response in HIV-infected children. Children in the lower percentile of weight, CD4 cell count, and CD4 cell per cent gain at 6 months of HAART were likely to have unsatisfactory immune response [6-13]. Studies are, however, scarce in assessing these potential clinical parameters such as the presence of baseline underweight, chronic diarrhea, tuberculosis, opportunistic infections or anemia as predictors of early immunologic response. Clinicians could possibly use these factors as an early alarming sign to identify children at higher risk of poor immune response to ART and target them for more intense monitoring and closer followup. Patients with insufficient CD4 cell recovery at six months of ART should undergo extensive clinical and laboratory assessments, as it could indicate poor adherence, which is believed to be the key element for the acquisition of antiretroviral drug resistance and finally lead to treatment failure $[10,11]$. In resource-limited settings, in which the number of drugs available is limited, maximizing the duration of existing lines of treatment, and identifying and addressing the reasons for poor response worth emphasized $[11,12]$. In this study, we mainly focused on factors predicting poor CD4 cell recovery during the first six months of ART.

\section{Objective}

To assess factors predicting suboptimal CD4 cell recovery during the first six months of ART in HIV infected children.

\section{Methods}

A retrospective cross sectional study was conducted by reviewing medical records of children living with HIV who are on ART at Tikur Anbessa Specialized Tertiary Hospital. The hospital is a teaching specialized and national tertiary hospital. Pediatric and child health department is one of the major departments delivering patient caring service, teaching and research activities under different unit categories. Pediatric infectious clinic is one of the functioning units of the department and highly overburden subspecialty clinics mainly delivering pediatric HIV/AIDS care and treatment.

\section{Sample}

There were a total of 1145 children living with HIV registered in pediatric HAART clinic at pediatric infectious Clinic at the time of data collection. About 503 patients have already been on HAART and around 405 patients were taking HAART for six months and above. Of factors affecting CD4 cell recovery, baseline under weight is one of the most important clinical variables occurring in about $50 \%$ of the cases as shown in most studies $[5,6]$. So, using single proportion formula, the sample size found to be 384 . Only 360 medical records with complete clinical and laboratory parameters were accessed for data extraction.

\section{Definition of suboptimal CD4 cell recovery}

Different literatures and guidelines define suboptimal CD4 recovery using different values. However, most guide lines including national guideline define suboptimal CD4 recovery as CD4 increment of less than $20 \%$ or $50 \mathrm{cell} / \mathrm{mL}$ of baseline $[2,3]$.

\section{Data Extraction and Statistical Analysis}

Data were extracted from the patients' medical records and enumerated to data retrieval form, and then were entered to EPI info software for clean-up and pre and post-HAART anthropometric interpretation and directly transferred to SPSS version 17 for further analysis of important variables, significance testing. Paired-t-test was used to compare pre and post-HAART CD4 cell count differences. Using logistic regression, we first determined univariate associations between demographic and clinical variables, which, based upon clinical observations and prior studies. The independent variables included: baseline CD4\%/count, baseline hemoglobin, Weight at baseline, at three and six months of and WHO clinical staging, presence of chronic diarrhea, ART regimen. We disaggregate age into two categories (under 5 and 5-14 years old) to control for the age-related difference in $\mathrm{CD} 4$ count/proportion. Multivariate logistic regression was used to assess factors possibly contributing for poor CD4 recovery. P value of less than 0.05 considered statistically significant.

\section{Results}

Medical records of 360 patients which were eligible for the study were retrieved from medical record office and data extracted. Males constitute $51 \%(183 / 360)$ while females were $49 \%$ (177/360). The minimum age at the start of ART was 4 months and the highest being 168 months (Interquartile age range 87-120 months).

Those who started on ART at the age of less than 12 months constitute the least number, $4.1 \%(15 / 360)$ and those who started treatment between 60-120 months were by far the largest $54.6 \%$ $(197 / 360)$. Baseline anthropometric interpretation showed that total patients with wasting were $42.6 \%$ with moderate and severe wasting being $20.4 \%$ and $1.5 \%$, respectively. Anemia was detected in $16.3 \%$ $(61 / 360)$ of patients at the start of HAART with the majority of the cases having a mild degree of anemia accounting for $81 \%(49 / 61)$ of the cases of anemia (Table 1).

About 206 (57.1\%) of patients were started on AZT-based nucleoside reverse transcriptase inhibitors (NRTI) while $132(36.7 \%)$ patients were taking $\mathrm{d} 4 \mathrm{~T}$ based regimen. There is no difference in degree of $\mathrm{CD} 4$ recovery among patient taking the two regimen ( $\mathrm{p}$ value is 0.134 ).

With regards to non-nucleoside reverse transcriptase inhibitors

\begin{tabular}{|c|c|c|c|c|}
\hline Base line value & Category & Male & Female & Total \\
\hline \multirow[t]{2}{*}{ Age category } & Under 5 years & 60 & 47 & $107(29.7 \%)$ \\
\hline & $5-14$ years & 123 & 130 & $253(70.3 \%)$ \\
\hline \multirow[t]{3}{*}{ Weight-for-age } & $<3$ rd centile & 88 & 101 & $189(52.5 \%)$ \\
\hline & 3rd-97th centile & 78 & 58 & $136(37.8 \%)$ \\
\hline & Above 97th centile & 17 & 18 & $35(9.7 \%)$ \\
\hline \multirow[t]{3}{*}{ Weight-for-height } & $<3$ rd centile & 85 & 100 & $185(51.4 \%)$ \\
\hline & 3rd-97th centile & 92 & 77 & $169(46.9 \%)$ \\
\hline & Above 97 th centile & 6 & 0 & $6(1.7 \%)$ \\
\hline \multirow{4}{*}{$\begin{array}{l}\text { WHO Clinical } \\
\text { Staging of AIDS }\end{array}$} & 1 & 7 & 2 & $9(2.6 \%)$ \\
\hline & II & 59 & 55 & $114(31.6 \%)$ \\
\hline & III & 88 & 95 & $183(51 \%)$ \\
\hline & IV & 28 & 26 & $54(14.8 \%)$ \\
\hline \multirow[t]{3}{*}{ CD4 cell category } & $>25 \%$ or $>500$ & 18 & 10 & $28(7.6 \%)$ \\
\hline & $15-25 \%$ or $200-500$ & 90 & 101 & $191(53.1 \%)$ \\
\hline & $<15 \%$ or $<200$ & 75 & 66 & $141(39.3 \%)$ \\
\hline Base anemia & & 29 & 31 & $60(16.7 \%)$ \\
\hline
\end{tabular}

Table 1: Demographic and base line values of some variables at initiation of HAART, Tikur Anbessa Tertiary Hospital, Addis Ababa Ethiopia, 2014. 
Citation: Sorsa A (2017) Predictors of Sub-Optimal CD4 Recovery during the First Six Months of Anti-Retroviral Treatment (ART) in HIV Infected Children: A Retrospective Cross Sectional Study from Tikur Anbessa Tertiary Hospital, Addis Ababa, Ethiopia. J Blood Lymph 7: 178. doi: $10.4172 / 2165-7831.1000178$

Page 3 of 5

(NNRTIs) as backbone about $72.4 \%(261 / 360)$ were taking NVP containing regimen while $21.4 \%$ (77/360) were on EFV-containing regimen. Still there is no difference in degree of CD4 recovery among patient taking the two regimen ( $\mathrm{p}$ value is 0.34 ). There were $57 / 360(15.8 \%)$ cases had documented chronic illness including new development of tuberculosis and chronic diarrhea, which accounts for the majority of cases and others were seizure disorder and chronic otitis media. About 10.7\% (39/360) of patients were treated for tuberculosis during first six months of HAART. Majority of patients $(53.1 \%)$ were having moderate immune suppression (CD4 cell count of 200-500 or CD4 cell per cent 15-25\%) at start of HAART while 39.3\% of cases were having severe immunosuppressant (CD4 cell count $<200$ or $<15 \%$ ) and (7.6\%) were having mild immune suppression while baseline WHO clinical stage II, III, and IV were $31.6 \%, 51 \%$ and $18.8 \%$ respectively (Table 2 and Figure 1). Baseline CD4 cell count ranged from 3-2003 cell $/ \mathrm{mL}$ with inter quartile range of $231-317 \mathrm{cell} / \mathrm{mL}$ and average CD4 cell count of 261 cell $/ \mathrm{mL}$. After six months of HAART, about $85 \%$ $(306 / 360)$ of patients were having CD4 cell increment of greater than $20 \%$ or $50 \mathrm{cell} / \mathrm{mL}$ of baseline value. Mean of CD4 cell count pre and post-HAART was compared; the mean CD4 cell count difference was 230, 95\% CI (199.414-260.613), and count ranged from 71-2300 c/mL with inter quartile range of $458-612 \mathrm{c} / \mathrm{mL}$ at six month of initiation of HAART, P-value $<0.001$. The mean weight gain at three and six months of HAART were found to be 1.00 and $1.50 \mathrm{~kg}$ with the mean weight difference of 0.772 and $1.80 \mathrm{~kg}, 95 \% \mathrm{CI}(0.588-0.957)$ and (1.60$2.0) \mathrm{P}<0.001$ respectively. Advanced $\mathrm{WHO}$ clinical staging and severe immunosuppression at start of HAART were adversely related CD4 recovery with statistically significant value. Similarly, Low baseline weight, presence of, presence of chronic diarrhea and poor weight gain at three and six months of ART found to have significantly detrimental impact on CD4 cell recovery (Table 3).

\begin{tabular}{|l|c|c|c|c|}
\hline Profile after HAART & Category & Male & Female & Total \\
\hline Rate of weight & $<5 \%$ & 101 & 110 & $211(58.7 \%)$ \\
\hline \multirow{2}{*}{$\begin{array}{l}\text { increment at three } \\
\text { months of HAART }\end{array}$} & $6-10 \%$ & 33 & 39 & $72(19.9 \%)$ \\
\hline Rate of weight & $>10 \%$ & 31 & 46 & $77(21.4 \%)$ \\
\hline increment at six months & $<5 \%$ & 59 & 64 & $123(34.2 \%)$ \\
\cline { 2 - 5 } of HAART & $5-10 \%$ & 51 & 63 & $114(31.6 \%)$ \\
\hline CD4 cell count or & $>10 \%$ & 68 & 65 & $123(34.2)$ \\
\hline \multirow{2}{*}{$\begin{array}{l}\text { percent at six month of } \\
\text { HAART }\end{array}$} & $15-25 \%$ or $200-500$ & 97 & 88 & $185(51.3 \%)$ \\
\cline { 2 - 5 } & $<15 \%$ or $<200$ & 16 & 17 & $33(9.3 \%)$ \\
\hline
\end{tabular}

Table 2: Patterns of weight gain and CD4 cell recovery at three and six month of HAART, Tikur Anbessa Tertiary Hospital, Addis Ababa Ethiopia, 2014.

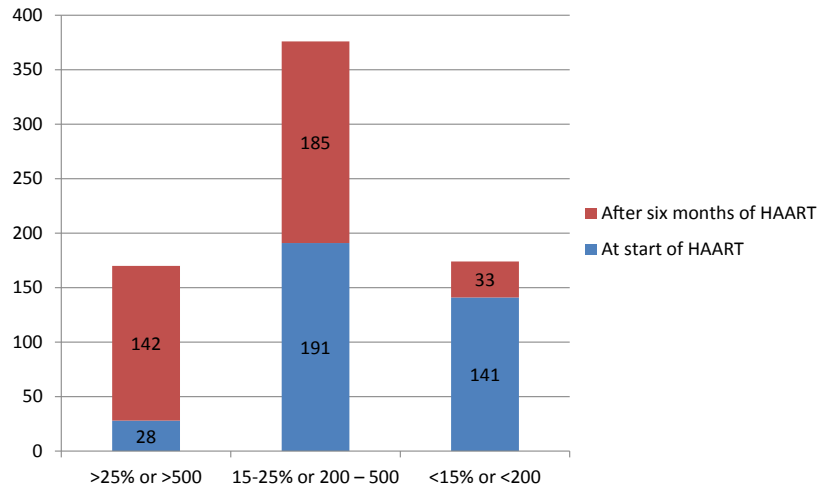

Figure 1: Distribution of CD4 cell category at baseline and after six months of HAART; Tikur Anbessa Tertiary Hospital, Addis Ababa Ethiopia, 2014.

\begin{tabular}{|c|c|c|c|}
\hline \multirow[t]{2}{*}{ Variables } & & \multicolumn{2}{|c|}{$\begin{array}{l}\text { CD4 cell recovery by }<20 \% \text { or } \\
<50 \text { cell } / \mathrm{mL} \text { of baseline }\end{array}$} \\
\hline & & $\begin{array}{l}\mathrm{N}=360, \text { Adjusted Odds } \\
\text { Ratio }(95 \% \mathrm{Cl})\end{array}$ & P-value \\
\hline \multirow[t]{2}{*}{ Base line weight } & $<3$ rd centile & $0.31(0.15-0.92)$ & 0.018 \\
\hline & $3^{\text {rd }}-97^{\text {th }}$ & 1 & \\
\hline \multirow[t]{3}{*}{ WHO clinical Staging } & II & $1.72(0.61-4.55)$ & 0.014 \\
\hline & II I \&IV & $4.76(1.71-10.00)$ & 0.006 \\
\hline & I & 1 & \\
\hline \multirow{3}{*}{$\begin{array}{l}\text { Base line CD4 count } \\
\text { category }\end{array}$} & $<15 \%$ or $<200 \mathrm{cell} / \mathrm{mL}$ & $4.35(2.89-11.23)$ & 0.025 \\
\hline & $\begin{array}{l}15-25 \% \text { or } 200-500 \\
\text { cell//mL }\end{array}$ & $1.78(0.47-6.25)$ & 0.015 \\
\hline & $>25 \%$ or $>500$ & 1 & \\
\hline \multirow[t]{2}{*}{ Age category } & $5-14$ years & $2.11(0.81-9.11)$ & 0.017 \\
\hline & $<$ 5years & 1 & \\
\hline \multirow{2}{*}{$\begin{array}{l}\text { Base line hemoglobin } \\
\text { level }\end{array}$} & $<10 \mathrm{~g} / \mathrm{dL}$ & $2.94(1.02-7.14)$ & 0.014 \\
\hline & $>10 \mathrm{~g} / \mathrm{dL}$ & 1 & \\
\hline \multirow{2}{*}{$\begin{array}{l}\text { Rate of weight gain at } \\
\text { three month of ART }\end{array}$} & $<10 \%$ & $2.50(1.05-5.00)$ & 0.012 \\
\hline & $>10$ & 1 & \\
\hline \multirow{2}{*}{$\begin{array}{l}\text { Rate of weight gain at } \\
\text { six month of ART }\end{array}$} & $<10 \%$ & $4.34(1.15-8.33)$ & 0.002 \\
\hline & $>10 \%$ & 1 & \\
\hline \multirow[t]{2}{*}{ Chronic diarrhea } & yes & $2.56(0.6-4.45)$ & 0.007 \\
\hline & No & 1 & \\
\hline
\end{tabular}

Table 3: Multivariate logistic regression showing predictors CD4 cell recovery by $<25 \%$ or $<50 \mathrm{cell} / \mathrm{mL}$ of baseline among patient at six months of HAART, Tikur Anbessa Tertiary Hospital, Addis Ababa Ethiopia, 2014.

\section{Discussion}

In our study, the mean CD 4 cell count increment is 230 cell $/ \mathrm{mL}$ with count range of 71-2300 c/mL and inters quartile range of $458-612 \mathrm{c} / \mathrm{mL}$ at six month of ART. The probability of having CD4 cell \% or count of $(>25 \%$ or $>500)$ at six month of ART is $40 \%$. This finding is higher than previous studies results with possible explanation that most previous studies were carried out on adult patients where CD4 lymphocytes physiologically decline with increasing age [1-4]. For instance the study conducted in South Africa which involved about 4000 adult patients showed that the probability of having CD4 count of $>200 \mathrm{cell} / \mathrm{mL}$ at twelve months of ART is about $51 \%$. The association between older age groups and poor immune recovery demonstrated in our study which is in congruence with other previous pediatric and adult reports [5,11]. This might be justified by too depleted thymus and other lymphoid tissues to repopulate the Tlymphocytes after initiation of ART in older age groups. On the other hand, in our study there is no relationship between gender of the patient and risk of adverse immune restoration though other studies were with discordant results; some reported male gender is associated with poor immune recovery others showed no gender difference [14-16]. Presence of chronic diarrhea during ART treatment is associated with poor CD4 cell recovery independent of nutritional status of the patient which is in agreement with most previous studies. The reason is not clearly identified so far but could be because of associated mal-absorption and poor adherence during the illness. Our study also showed that the presence of anemia at baseline $(\mathrm{Hgb}<10 \mathrm{~g} / \mathrm{dL})$ is related with poor immune system regeneration which is in concordant with similar studies from other sites $[13,15,17,18]$. For example, study from South Africa showed that children living with HIV who started on ART with lower baseline hemoglobin had significant risk of adverse CD4 cell recovery $(\mathrm{OR}=0.87$ for each $1 \mathrm{~g} /$ $\mathrm{dL}$ decrease in hemoglobin; 95\%CI 0.75-0.99) [6,7]. This association is scientifically plausible as there is clear interaction between elemental 
Citation: Sorsa A (2017) Predictors of Sub-Optimal CD4 Recovery during the First Six Months of Anti-Retroviral Treatment (ART) in HIV Infected Children: A Retrospective Cross Sectional Study from Tikur Anbessa Tertiary Hospital, Addis Ababa, Ethiopia. J Blood Lymph 7: 178. doi: 10.4172/2165-7831.1000178

Page 4 of 5

iron in immune system. Our research findings of lower baseline CD4 cell value predicts poor six month CD4 cell recovery is supported with other cohort studies. A large cohort involving 861 adult patients living with HIV in Spain showed that patients with baseline CD4 count of 200 and of 201 to 350 cells $/ \mathrm{mm} 3$ had a significantly lower chance of achieving CD4 count of 500 cells $/ \mathrm{mm}^{3}$ compared with patients with baseline CD4 350 cells $/ \mathrm{mm}^{3}$ and above [14,19].

This study also revealed that weight gain of less $10 \%$ at three and six months of HAART were independently predicting poor CD4 recovery which is also in compatible with other research findings. The poor weight gain could indicate poor adherence, an advancing disease stage or underlying opportunistic infection implying that the patient should undergo extensive clinical and laboratory evaluation. Similar study in South Africa and elaborated lower percentiles of weight gain after 6 months of ART were associated with poor subsequent treatment outcomes and higher risk of mortality independent of other baseline characteristics $[17,20,21]$. Likewise, a low baseline weight was an independent predictor of an adverse outcome in our study, which is in agreement with other observational studies where patients with weight less than $3^{\text {rd }}$ centile had a two-fold increased risk of dying [22]. Our study didn't depict association between ART regimen and risk of poor CD4 restoration which could be explained by almost all ( $94 \%$ of the patients) were taking two NRTI and one NNRTI to see the difference between regimens. However, previous studies were reporting discordant results. Some studies reported that AZT or $\mathrm{d} 4 \mathrm{~T}$ based regimen were associated with adverse immune reconstitution others showed NRTI regimens were associated with poorer recovery of CD4 count [15].

\section{Conclusion}

Our study demonstrated that advanced clinical stage of the disease, severe degree of immunosupression, presence of anemia at baseline and presence of chronic diarrhea, poor weight gain during first six months of HAART were factors adversely affect the trends of early CD4 recovery.

\section{Ethical approval and consent to participate}

Ethical clearance was obtained from the department of institutional review board of Addis Ababa University College of Health Science. Letter of permission was given from the department of pediatrics and child health to retrieve medical records. The records of patients were kept at safe place and information collected from the record was kept confidential. Patient with possible poor treatment response were traced back and intervened accordingly.

\section{Funding}

As we sponsored the research project ourselves for all parts of research work, there is no conflict of interest from anybody.

\section{Competing Interests}

The authors declare that they have no competing interests.

\section{Authors' Contributions}

As involved in the preparation of the study design, participated in data collection, data entry and data analysis as well as manuscript preparation.

\section{Acknowledgements}

We would like to thank Addis Ababa University College of Health Science, department of pediatrics and child health for allowing us to conduct the study. I would like to extend my heartfelt acknowledgement to Dr Tigist Bacha for her unreserved valuable comments to finalize this manuscript.

\section{References}

1. Simbarashe $T$, Mhairi M, Alana T B (2014) Poor CD4 recovery and risk of subsequent progression to AIDS or death despite viral suppression in a South African cohort. Journal of the International AIDS Society 17: 18651.

2. Brian CZ, Thuli P, Holly MZ (2012) Predictors of Poor CD4 and Weight Recovery in HIV Infected Children Initiating ART in South Africa. PLoS ONE 7: e33611.

3. Lopez de D, Kristien V, Larissa O, Iglesias D, Echevarría J, et al. (2008) Predictors of CD4+ cell count response and of adverse outcome among HIVinfected patients receiving highly active antiretroviral therapy in a public hospital in Peru. International Journal of Infectious Diseases 12: 325-331.

4. Ayalu AR, Sibhatu B, Amare D, Gebre B, Deribe K (2013) Predictors of Change in CD4 Lymphocyte Count and Weight among HIV Infected Patients on AntiRetroviral Treatment in Ethiopia: A Retrospective Longitudinal Study. PLoS ONE 8: e58595.

5. Derseh Gezie LD (2016) Predictors of CD4 count over time among HIV patients initiated ART in Felege hiwot Referral Hospital, northwest Ethiopia: multileve analysis. BMC Res Notes 9: 377.

6. Addisu A, Dagim A, Tadele E, Alemayehu A, Alemayehu M (2015) CD4 Cell Count Trends after Commencement of Antiretroviral Therapy among HIV Infected Patients in Tigray, Northern Ethiopia: A Retrospective Cross-Sectional Study. PLOS ONE 10: e0122583.

7. Ingrid Eshun-W, Jantjie JT, Jean BN (2012) Sub-Optimal CD4 T-Lymphocyte Responses among HIV Infected Patients who Develop TB during the First Year of ART. J AIDS Clinic Res 3: 135

8. Crum-C NF, Mollie R, Lynn EE (2011) Impact of Weight on Immune Cell Counts among HIV-Infected Persons. Clinical and Vaccine Immunology 18: 940-946.

9. Thanyawee $P$, Stephen JK, Jintanat A, Ananworanich I, Bunupuradah T et al. (2009) Pattern and Predictors of Immunologic Recovery in Human Immunodeficiency Virus-Infected Children Receiving Non-Nucleoside Reverse Transcriptase Inhibitor-Based Highly Active Antiretroviral Therapy. Pediatr Infect Dis J 28: 488-492.

10. Mihiretu MK, Desalegn TZ, Berihun MZ (2014) Predictors of CD4 Count Changes after Initiation of Antiretroviral Treatment in university of Gondar Hospital, Gondar in Ethiopia. Clinical Research in HIVI AIDS 1: 1008.

11. Ethiopia Ministry of Health (2012) Guidelines for Pediatric HIVIAIDS Care and Treatment in Ethiopia (1st edn).

12. Theophilus BK, Michael O, Mohamed M, Nguah SB, Obeng-Baah J (2015) Pattern and predictors of immunologic recovery in HIV infected patients. BMC Res Notes 8: 413.

13. Gilbert RK, Hansjakob F, Bruno L, Perrin L, Opravil M, et al. (2005) Characteristics, Determinants, and Clinical Relevance of CD4 T Cell Recovery to $<500$ Cells $/ \mathrm{mL}$ in HIV Type 1-Infected Individuals Receiving Potent Antiretroviral Therapy. Clinical Infectious Diseases 41:361-372.

14. Tigist B, Birkneh T, Alemayehu W (2012) Predictors of treatment failure and time to detection and switching in HIV-infected Ethiopian children receiving first line anti-retroviral therapy. BMC Infectious Diseases 12: 197.

15. Third International Work Shop on HIV in paediatrics (2011) Immediate ART no better than deferred in Asian kids with moderate CD4 loss.

16. Zanoni BC, Thuli P, Holly M, Zanoni, Holly F, et al. (2008) Predictors of Poor CD4 and Weight Recovery in HIV-Infected Children Initiating ART in South Africa. PLoS ONE 7: e33611.

17. Chiappini E, Galli L, Tovo P, Gabiano C, Lisi C, et al. (2009) Five-year followup of children with perinatal HIV-1 infection receiving early highly active antiretroviral therapy. BMC Infectious Diseases 9: 140.

18. Ahoua L, Gunar G, Loretxu P (2009) Risk factors for virological failure and subtherapeutic antiretroviral drug. BMC Infectious Diseases 9: 334-338.

19. Yoann M, Szumilin E, Genevier C, Fontanet A (2009) Weight gain at 3 months of antiretroviral therapy is strongly associated with survival: Evidence from two developing countries. AIDS 23: 853-861.

20. Marcel Y, Van R, Moultrie H, Meyers T (2010) Six-month gain in weight, height and CD4 predict subsequent antiretroviral treatment responses in HIV-infected South African children. AIDS 24: 139-146. 
Citation: Sorsa A (2017) Predictors of Sub-Optimal CD4 Recovery during the First Six Months of Anti-Retroviral Treatment (ART) in HIV Infected Children: A Retrospective Cross Sectional Study from Tikur Anbessa Tertiary Hospital, Addis Ababa, Ethiopia. J Blood Lymph 7: 178. doi: 10.4172/2165-7831.1000178

Page 5 of 5

21. Elijah P (2010) Monitoring Antiretroviral Therapy in HIV-Infected Children in Resource-Limited Countries: A Tale of Two Epidemics. AIDS Res Treat 2011: 280901.
22. Lilian O, Marcelle M, Camargos LS, Amarall LC, Goulart EMA (2011) Impact of HAART on growth and hospitalization rates among HIV-infected children. $J$ Pediatr (Rio J) 87: 131-137. 